\title{
Comparative adsorption isotherms and modeling of methylene blue onto activated carbons
}

\author{
Meriem Belhachemi • Fatima Addoun
}

Received: 15 April $2011 /$ Accepted: 9 September 2011/Published online: 27 September 2011

(C) The Author(s) 2011. This article is published with open access at Springerlink.com

\begin{abstract}
The adsorption of methylene blue (MB) on activated carbons prepared from date stones with different degree of activation has been investigated. Equilibrium adsorption data of MB was carried out at $298 \mathrm{~K}$. Four isotherm models (Freundlich, Langmuir, Redlich-Peterson and Sips) were tested for modeling the adsorption isotherms by nonlinear method. The three-parameter equations (Redlich-Peterson and Sips) showed more applicability than the two-parameter equations (Freundlich and Langmuir), which can be explained by the fact that these have three adjustable parameters. The best fit was achieved with the Redlich-Peterson equation according to the high value of correlation coefficient. All the samples were capable of retaining the $\mathrm{MB}$, with the best result being reached by the sample with higher burn-off. Date stones activated carbon showed high adsorption capacity of $460 \mathrm{mg} / \mathrm{g}$, calculated from the Sips isotherm model.
\end{abstract}

Keywords Activated carbon - Surface properties · Nonlinear regression · Equilibrium isotherm

\footnotetext{
M. Belhachemi $(\bowtie)$

Laboratoire de fiabilité et structure des matériaux. Faculté de Sciences et Technologie, Université de Bechar, 08000 Bechar, Algeria

e-mail: bel_meriem@yahoo.fr

M. Belhachemi - F. Addoun

Laboratoire d'étude physico-chimique des matériaux et application à l'environnement, Faculté de Chimie, USTHB, B.P.32, 16111 Bab Ezzouar Alger, El Alia, Algeria
}

\section{Introduction}

Considering both the volume and chemical composition of the discharged effluent, the textile, dyeing, pulp and paper, and printing industries are the major polluters among the industrial sectors (Easton 1995). Pulp and textile industries consume considerable amounts of water in their manufacturing processes and hence produce large amounts of wastewater. Effluents from the industries are also characterized by their low biochemical oxygen demand (BOD) and high color content. Textile industry is particularly known for its high water consumption, as well as for the usage of variety and large quantity of chemicals throughout different process stages (Bansal and Goyal 2005; Robinson et al. 2001).

Adsorption has been extensively studied as a costeffective method for removing a wide variety of hazardous materials, such as dyes and heavy metals, from aqueous solutions. The most widely used adsorbent for separating the pollutants is activated carbon. Most adsorption research focused on the isotherm, kinetic, and thermodynamic processes. For the adsorption process, an analysis of the isotherm data is important because the isotherms describe equilibrium relationships between adsorbent and adsorbate, usually the ratio between the quantity adsorbed and that remaining in the solution at a fixed temperature at equilibrium. The distribution of dye between the adsorbent and dye solution, when the system is in a state of equilibrium, is important in establishing the capacity of the adsorbent for the dye (Mall et al. 2006). The capacity of activated carbon for a given pollutant is usually determined by carrying out an adsorption isotherm.

This work investigates the adsorption of methylene blue (MB) onto activated carbons produced from date pits using equilibrium isotherms. A further aim is to describe

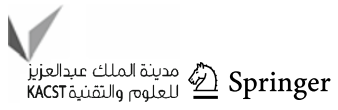


equilibrium data using equilibrium isotherm models. The isotherm constants for the Langmuir, the Freundlich, the Redlich-Peterson, and Sips isotherms have been calculated using nonlinear regression with the help of Origin (Version 8) software program.

\section{Experimental}

\section{Adsorbent}

Any cheap material with a high carbon content low in ash can be used as a new material for production of activated carbon. Date pits have a low ash content $1.7 \%$.

Four activated carbons were tested for the adsorption of MB in solution. The materials were prepared in our laboratory by physical activation of date stones with $\mathrm{CO}_{2}$ $\left(150 \mathrm{ml} \mathrm{min}{ }^{-1}\right)$ at $800^{\circ} \mathrm{C}$ using different activation times to cover burn-off range 16-64\%. The prepared activated carbons were named as letter $\mathrm{C}$ followed by the burn-off. The details of the activation process have been described elsewhere (Belhachemi et al. 2009). After activation the ash content increases and does not exceed $6 \%$ for all activated carbons. The samples were washed with a dilution $\mathrm{HCl}$ solution in order to remove the ash components. Subsequently, the samples were repeatedly washed with distilled water until neutral $\mathrm{pH}$. The samples were then dried at $120^{\circ} \mathrm{C}$, and finally kept in hermetic bottles for further experiments.

The textural characterization of activated carbons was carried out by nitrogen and dioxide carbon adsorption at -196 and $0^{\circ} \mathrm{C}$ respectively, using a static manometric apparatus. The apparent surface area was obtained using the BET method. The micropore volume $\left(V_{\mathrm{o}}\right)$ was deduced from the $\mathrm{N}_{2}$ adsorption data using the Dubinin-Raduskevitch (DR) equation, while the mesopore volume $\left(V_{\text {meso }}\right)$ was obtained as the difference between the total pore volume $\left(V_{\mathrm{T}}\right)$ adsorbed at $p / p_{\mathrm{o}}=0.95$ and the micropore volume $\left(V_{\mathrm{o}}\right)$. The pore volume corresponding to the narrow microporosity $\left(V_{0}\right)$ was obtained after application of the DR equation to the $\mathrm{CO}_{2}$ adsorption data.

Temperature-programmed desorption experiments and infra-red spectroscopy methods (FTIR) were carried out to evaluate the amount and nature of the oxygen surface groups present in each sample. The TPD profiles were obtained using a vertical quartz reactor inside an electric furnace, connected to a quadrupole mass spectrometer (Balzer MSC200). About $100 \mathrm{mg}$ of sample were introduced into it and heat treated at $10^{\circ} \mathrm{C} \mathrm{min}{ }^{-1}$ from room temperature up to $1,050^{\circ} \mathrm{C}$ under a flow of helium, and the evolved gasses were analyzed. The amounts of $\mathrm{CO}$ and $\mathrm{CO}_{2}$ evolved during the heat treatment were calculated by integration of the desorption profiles. Both $\mathrm{CaC}_{2} \mathrm{O}_{4} \cdot \mathrm{H}_{2} \mathrm{O}$ and known mixtures of both gasses were used as references for the calibration of the spectrometer. The FTIR spectra have been recorded in the range $4,000-500 \mathrm{~cm}^{-1}$. The FTIR spectra of the samples were obtained using $\mathrm{KBr}$ wafers containing $0.5 \mathrm{~g}$ carbon.

\section{Adsorption isotherm}

Adsorption was determined by batch method, which is simple and easy to perform. In batch method, a fixed amount of the adsorbent $(0.01 \mathrm{~g})$ was added to $10 \mathrm{ml}$ of dye solution of varying concentrations taken in well-closed flasks. Then, all the flasks were shaken for $24 \mathrm{~h}$. It was previously checked that this period of time was enough to reach equilibrium adsorption. After shaking, the suspensions were centrifuged at 2,000 rpm for $2 \mathrm{~min}$. The solutions were carefully decanted to be analyzed using a UV/ VIS spectrophotometer (Unicam helios $\delta$ ), at $665 \mathrm{~nm}$, which was the maximum wave length for MB.

The amount of MB adsorbed was calculated based on the following equation:

$q_{\mathrm{e}}=\frac{\left(C_{0}-C_{\mathrm{e}}\right) V}{m}$

where $q_{\mathrm{e}}$ is the amount of dye adsorbed in activated carbon, $C_{\mathrm{o}}$ and $C_{\mathrm{e}}$ the initial and equilibrium concentrations of MB solutions, $m$ the amount of adsorbent and $V$ is the volume of solution. The solution $\mathrm{pH}$ was used without adjustment for all experiments. Over the range of concentrations used, the $\mathrm{pH}$ of the $\mathrm{MB}$ solutions was constant at 6.2.

Adsorption equilibrium data which express the relationship between mass of adsorbate adsorbed per unit weight of adsorbent and liquid-phase equilibrium concentration of adsorbate are represented by adsorption isotherms and provide important design data of adsorption system. The equilibrium data for the removal of MB in the present investigation were analyzed using the two-parameter model, Langmuir, Freundlich and three-parameter model, Redlich-Peterson and Sips equations (Freundlich 1906; Langmuir 1916; Redlich and Peterson 1959; Umpleby et al. 2001)

\section{Langmuir isotherm}

The Langmuir adsorption isotherm is based on monolayer, uniform, and finite adsorption site assumptions, therefore a saturation value is reached beyond which no further adsorption takes place. It also assumes that there is no interaction between the molecules adsorbed on neighboring sites. The Langmuir equation which is valid for monolayer adsorption onto a surface with a finite number of identical sites is given by: 
$q_{\mathrm{e}}=\frac{Q_{\mathrm{L}} K_{\mathrm{L}} C_{\mathrm{e}}}{1+K_{\mathrm{L}} C_{\mathrm{e}}}$

where $C_{\mathrm{e}}$ is the concentration of the dye solution at equilibrium $(\mathrm{mg} / \mathrm{L}), q_{\mathrm{e}}$ is the amount of dye adsorbed per unit mass of adsorbent $(\mathrm{mg} / \mathrm{g})$, and $K_{\mathrm{L}}$ is the constant related to the free energy of adsorption $(\mathrm{L} / \mathrm{mg}) . Q_{\mathrm{L}}$ is the maximum adsorption capacity.

The essential characteristic of the Langmuir isotherm can be expressed in terms of a dimensionless constant called equilibrium parameter (Hall et al. 1966):

$R_{\mathrm{L}}=\frac{1}{\left(1+K_{\mathrm{L}} C_{0}\right)}$

where $K_{\mathrm{L}}$ is the Langmuir constant and $C_{0}$ is the highest initial dye concentration $(\mathrm{mg} / \mathrm{L})$. The value of $R_{\mathrm{L}}$ indicates the type of isotherm to be either favorable $\left(0<R_{\mathrm{L}}<1\right)$, linear $\left(R_{\mathrm{L}}=1\right)$, unfavorable $\left(R_{\mathrm{L}}>1\right)$, or irreversible $\left(R_{\mathrm{L}}=0\right)$.

\section{Freundlich isotherm}

Freundlich isotherm is an empirical equation for multilayer, heterogeneous adsorption sites. The Freundlich equation is commonly given by:

$q_{\mathrm{e}}=K_{\mathrm{F}} C_{\mathrm{e}}^{1 / n_{\mathrm{F}}}$

where $q_{\mathrm{e}}$ is the amount of solute adsorbed per unit weight of adsorbent $(\mathrm{mg} / \mathrm{g}), C_{\mathrm{e}}$ is the equilibrium concentration of solute in the bulk solution $(\mathrm{mg} / \mathrm{L}), K_{\mathrm{F}}$ is a Freundlich constant indicative of the relative adsorption capacity of the adsorbent $(\mathrm{mg} / \mathrm{g})$, and $1 / n_{\mathrm{F}}$ is the heterogeneity factor.

\section{Redlich-Peterson isotherm}

Redlich-Peterson equation included three adjustable parameters into an empirical isotherm. This equation is widely used as a compromise between Langmuir and Freundlich systems. The equation for this model is:

$q_{\mathrm{e}}=\frac{K_{\mathrm{RP}} C_{\mathrm{e}}}{1+a_{\mathrm{R}} C_{\mathrm{e}}^{\beta}}$

where $K_{\mathrm{RP}}$ and $\beta$ are the $\mathrm{R}-\mathrm{P}$ constants. When the value of $\beta$ is equal to 1 , the above equation is reduced to the Langmuir isotherm, while it reduced to a Freundlich isotherm, in case the value of the parameter $a_{\mathrm{R}} C_{\mathrm{e}}^{\beta}$ is much bigger than 1 . The ratio of $K_{\mathrm{RP}} / a_{\mathrm{RP}}$ indicates the adsorption capacity.

\section{Sips isotherm}

The nonlinear Sips (Freundlich-Langmuir) isotherm equation can be represented as:
$q_{\mathrm{e}}=\frac{Q_{\mathrm{S}} K_{\mathrm{S}} C_{\mathrm{e}}^{n_{\mathrm{S}}}}{1+K_{\mathrm{S}} C_{\mathrm{e}}^{n_{\mathrm{S}}}}$

where $K_{\mathrm{S}}$ is equilibrium constant. If the value of $n_{\mathrm{S}}$ is equal to 1 then this equation will become a Langmuir equation. Alternatively, as either $C_{\mathrm{e}}$ or $K_{\mathrm{S}}$ approaches 0 , this isotherm reduces to the Freundlich isotherm.

\section{Results and discusion}

Characterization of activated carbons

Table 1 reports the textural characteristics obtained from the $\mathrm{N}_{2}$ and $\mathrm{CO}_{2}$ adsorption isotherms at $77 \mathrm{~K}$ and $273 \mathrm{~K}$, respectively. The activation with $\mathrm{CO}_{2}$ produces both the opening of new micropores together with the broadening and deepening of the existing ones. The broadening of the microporosity is clearly reflected by comparing the difference between $V_{0}\left(\mathrm{~N}_{2}\right)$ and $V_{\mathrm{T}}$, the development of mesopore volume and also considering the variation of the relative ratio $V_{0}\left(\mathrm{~N}_{2}\right) / V_{\mathrm{T}}$ (percentage of microporosity) with burn-off. In fact, the activated C64 simple exhibits the highest BET surface area $\left(S_{\mathrm{BET}}: 1,669 \mathrm{~m}^{2} / \mathrm{g}\right)$, as well the highest micropore $\left(0.67 \mathrm{~cm}^{3} / \mathrm{g}\right)$ and total $\left(0.91 \mathrm{~cm}^{3} / \mathrm{g}\right)$ pore volume.

The amount and nature of the oxygen surface groups on the different activated carbons has been analyzed by temperature-programmed desorption experiments. In this sense, Fig. 1a, b shows the $\mathrm{CO}_{2}$ and $\mathrm{CO}$ desorption profiles for the different activated carbons in the $25-1050^{\circ} \mathrm{C}$ temperature range. Additionally, Table 2 reports the total amount of oxygen surface groups evolved both as $\mathrm{CO}_{2}$ and $\mathrm{CO}$. Although the TPD profile for $\mathrm{CO}_{2}$ is quite complex in all cases, the contribution of the more acidic groups is quite small as compared to the amount of $\mathrm{CO}$ evolved (see Table 2).

According to Fig. 1a, an increase in burn-off has mainly no effect in the total amount of oxygen surface groups evolved as $\mathrm{CO}_{2}$ (carboxylic acid, lactone, etc.), i.e. the least stable groups. However, the amount of $\mathrm{CO}$, i.e. the most stable groups evolved increase with degree of activation (see Fig. 1b). This effect is clearly reflected in the $\mathrm{CO} / \mathrm{CO}_{2}$ ratio, which increases continuously with the burn-off. $\mathrm{CO}$ desorption at high temperature $\left(>900^{\circ} \mathrm{C}\right)$, are attributed to the decomposition of carbonyl, quinones and pyrone type groups which have basic nature (Figueiredo et al. 1999; Órfão et al. 2006).

The FTIR spectra of date pits activated carbons with various burn-off are shown in Fig. 2. The spectrum displayed the following bands: $\mathrm{O}-\mathrm{H}$ stretching of the hydroxyl of the alcohols groups: $3,500 \mathrm{~cm}^{-1} ; \mathrm{N}-\mathrm{H}$ stretching: 1,480 and $1,560 \mathrm{~cm}^{-1} ; \mathrm{C}-\mathrm{O}$ stretching of ethers: $1,100 \mathrm{~cm}^{-1}$ 
Table 1 Specific surface area and pore volume calculated from the $\mathrm{N}_{2}$ and $\mathrm{CO}_{2}$ adsorption isotherms at $77 \mathrm{~K}$ and $273 \mathrm{~K}$, respectively, for activated carbons

\begin{tabular}{lllllll}
\hline Activated Carbon & $S_{\text {BET }}\left(\mathrm{m}^{2} \mathrm{~g}^{-1}\right)$ & $V_{0}\left(\mathrm{~N}_{2}\right)\left(\mathrm{cm}^{3} \mathrm{~g}^{-1}\right)$ & $V_{\text {meso }}\left(\mathrm{cm}^{3} \mathrm{~g}^{-1}\right)$ & $V_{\mathrm{T}}\left(\mathrm{cm}^{3} \mathrm{~g}^{-1}\right)$ & $V_{0}\left(\mathrm{~N}_{2}\right) / V_{\mathrm{T}}$ & $V_{0}\left(\mathrm{CO}_{2}\right)\left(\mathrm{cm}^{3} \mathrm{~g}^{-1}\right)$ \\
\hline C16 & 685 & 0.27 & 0.03 & 0.30 & 0.90 & 0.27 \\
C28 & 831 & 0.33 & 0.05 & 0.38 & 0.86 & 0.32 \\
C37 & 1,069 & 0.44 & 0.08 & 0.52 & 0.84 & 0.36 \\
C64 & 1,669 & 0.67 & 0.24 & 0.91 & 0.73 & 0.41 \\
\hline
\end{tabular}
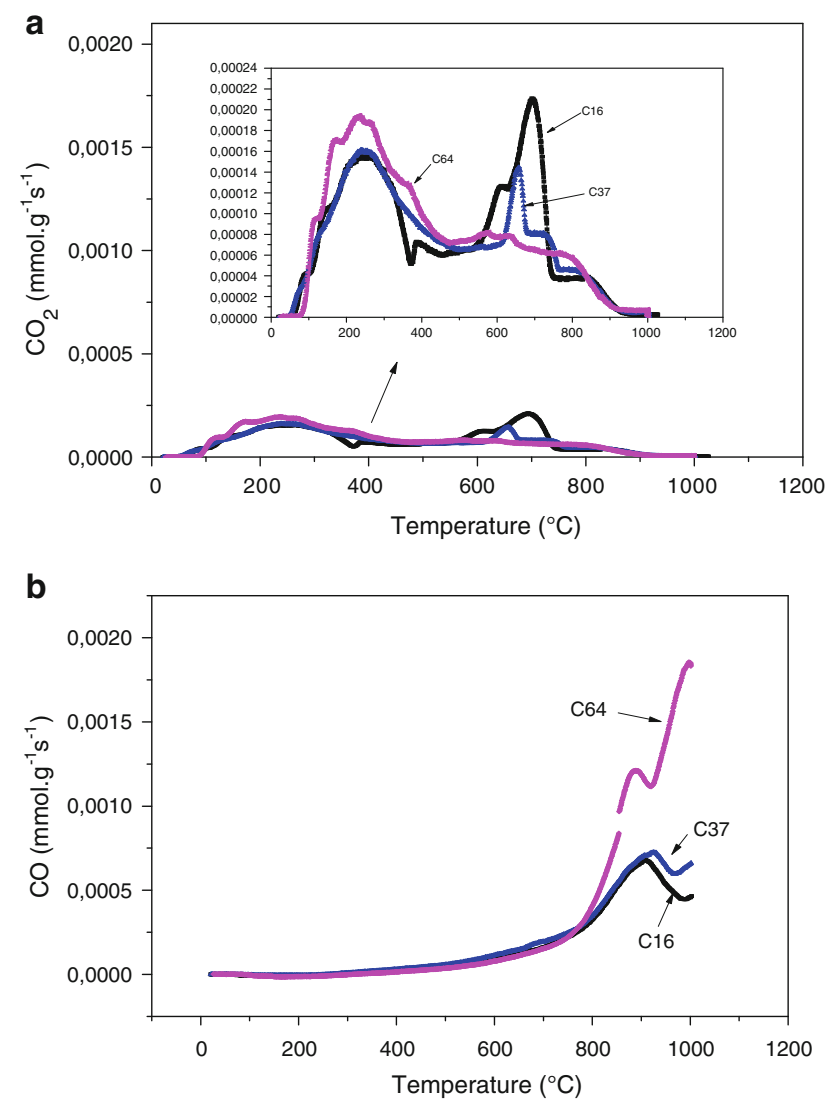

Fig. $1 \mathrm{CO}_{2}$ and $\mathrm{CO}$ temperature-programmed desorption profiles for activated carbons $\mathrm{C} 16, \mathrm{C} 37$ and $\mathrm{C} 64\left(\mathrm{CO}_{2}\right.$ profiles inset with large scale)

Table 2 Amount of $\mathrm{CO}$ and $\mathrm{CO}_{2}$ evolved during TPD experiment

\begin{tabular}{llll}
\hline Carbons & $\mathrm{CO}_{2}$ & $\mathrm{CO}$ & $\mathrm{CO} / \mathrm{CO}_{2}$ \\
\hline $\mathrm{C} 16$ & 0.41 & 0.89 & 2.1 \\
$\mathrm{C} 28$ & 0.45 & 1.13 & 2.5 \\
$\mathrm{C} 37$ & 0.43 & 1.17 & 2.7 \\
$\mathrm{C} 64$ & 0.42 & 1.61 & 4.0 \\
\hline
\end{tabular}

(Shafeeyan et al. 2010). The disappearance of bands and the decrease of others suggest that the aromaticity of the material increases during the activation and the least stable groups disappears; this result is consistent with TPD experiments.

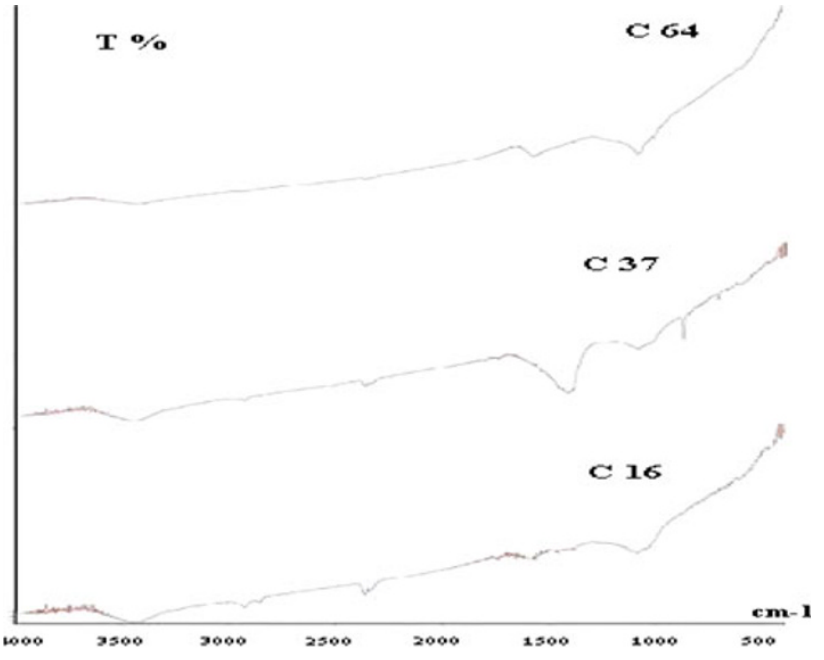

Fig. 2 FTIR spectra for activated carbons C16, C37 and C64

\section{Adsorption Isotherm Studies}

Adsorption isotherms were analyzed according to the nonlinear form of Langmuir, Freundlich, Redlich-Peterson and Sips isotherms, using origin software. The development of computer technology facilitated the application of the nonlinear optimization method as an alternative to determine the isotherm parameter values. This method does not transform data sets; hence, no distortions are created in the original error distribution. Comparisons of linear and nonlinear regressions often concluded that the best parameter estimates were returned by nonlinear optimizations (Allen et al. 2003; Boulinguiez et al. 2008; Ho 2004). The results for the four activated carbons are presented in Fig. $3 \mathrm{a}$ and Fig. $3 \mathrm{~b}$ shows the fit of the isotherm models to the experimental data for the adsorption of MB onto activated carbon $\mathrm{C} 28$. The isotherms (Fig. 3a) are of the same type. They are characterized by a large increase in the amount adsorbed at low concentrations, decreasing around an equilibrium concentration, and followed by a tendency for the formation of a plateau when the concentration is higher. Comparing isotherms (C16, C28, C37 and C64), it is clear that the activation process produces strong changes in the amount of MB adsorbed. Interestingly, the amount of MB adsorbed increases with the degree of activation. In fact, the activation treatment with $\mathrm{CO}_{2}$ gives rise to the 

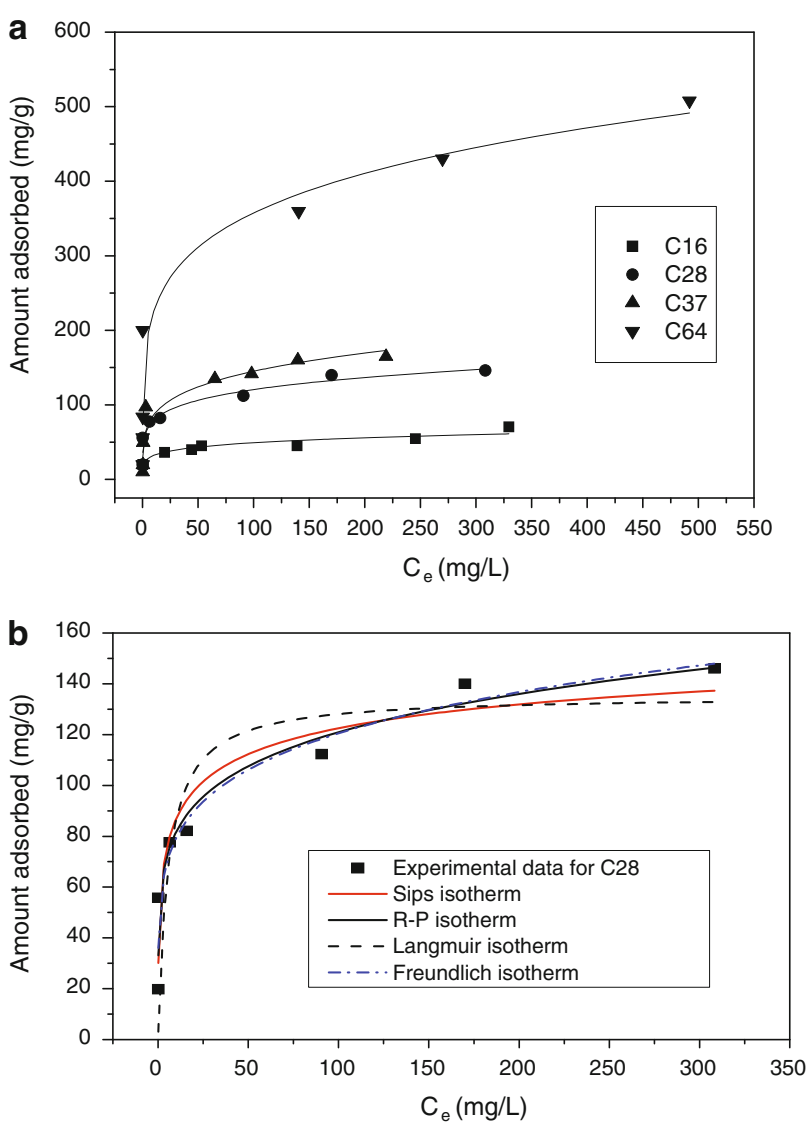

Fig. 3 a Adsorption isotherms of $\mathrm{MB}$ on date pits activated carbons at $25 \mathrm{C}$ (Initial dye concentration $30-1,000 \mathrm{mg} \mathrm{L}^{-1}$, contact time 24 $\mathrm{h}$, adsorbent dosage $10 \mathrm{~g} \mathrm{~L}^{-1}, \mathrm{pH}=6.2$ ). b Model fit of adsorption isotherm of MB adsorption onto C28 activated carbon (Initial dye concentration 30-600 $\mathrm{mg} \mathrm{L}^{-1}$, contact time $24 \mathrm{~h}$, adsorbent dosage $10 \mathrm{~g} \mathrm{~L}^{-1}, \mathrm{pH}$ 6.2)

development of porosity through the opening of new micropores together with the deepening and enlargement of the existing ones (see Table 1).

The mechanism of uptake of $\mathrm{MB}$ on activated carbons can be grouped into nonelectrostatic and electrostatic interactions. Activated carbons depend on the $\mathrm{pH}$ of the solution and the $\mathrm{pH}_{\mathrm{PZC}}$ ( $\mathrm{pH}$ of point of zero charge of activated carbon). Thus, the carbons surface is positively charged at $\mathrm{pH}<\mathrm{pH}_{\mathrm{pzc}}$ favoring the adsorption of anionic species and negatively charged at $\mathrm{pH}>\mathrm{pH}_{\mathrm{pzc}}$, which will favor the adsorption of cationic species (Rodriguez-Reinoso 1998).
According to the TPD results the activated carbons have basic character. Additionally, the $\mathrm{pH}_{\mathrm{pzc}}$ value of all samples exceeds 7.5 and is superior of the $\mathrm{pH}$ value of MB solution (6.2). Indeed the activated carbons are positively charged and $\mathrm{MB}$ is a basic dye, dissolved in water it is positively charged. Then, the dispersive interactions between the delocalized $\pi$-electrons on the surface of activated carbons and the free electrons of the dye molecule present in aromatic rings play a dominant role in the adsorption mechanism.

\section{Langmuir and Freundlich equations}

The results obtained by the application of the two-parameter model, Langmuir and Freundlich equations are presented in Table 3. From this table, the correlation coefficients for Freundlich isotherm are significantly high than that of Langmuir isotherm for samples C16, C28 and C64. A good fit of this equation reflects heterogeneous surface. However, adsorption of $\mathrm{MB}$ on activated carbon $\mathrm{C} 37$ agrees with Langmuir model. The analysis by considering the two parameters $Q_{\mathrm{L}}$ and $K_{\mathrm{F}}$ which are measures of adsorption capacity, it can be seen that there is a significant increase in the Langmuir monolayer capacity with increasing degree of activation, which is consistent with the increase of the pore volume and surface area of those samples (as can be seen in Table 1).

To further explore the effect of the porous structure in the adsorption of MB, Fig. 4 represents the amount of MB adsorbed $(\mathrm{mg} / \mathrm{g})$ as a function of (a) the total micropore volume and (b) the mesopore volume, obtained from the $\mathrm{N}_{2}$ adsorption isotherms $(77 \mathrm{~K})$. There is in, both cases, an increase in the amount adsorbed with the pore volume. The adsorption capacity for $\mathrm{MB}$ is an increasing function of the extent of activation, this shows that the microporosity, the surface area and mesoporosity, are the factors defining the adsorption capacity for MB in this study. Similar results have been reported for adsorption of MB on activated carbons (Altenor et al. 2009; Gaspard et al. 2007). According to the values of $R_{\mathrm{L}}$, all the systems show favorable adsorption of $\mathrm{MB}$, i.e., $0<R_{\mathrm{L}}<1$. The low values of $R_{\mathrm{L}}$ indicate high and favorable adsorption of MB onto activated carbons.

In relation to the Freundlich equation, it can be seen from Eq. (4) that the constant $K_{\mathrm{F}}$ should be equal to the amount adsorbed for $C_{\mathrm{e}}$ equal to $1 \mathrm{mg} / \mathrm{L}$ (as these are the
Table 3 Freundlich and Langmuir isotherms constants for the adsorption of $\mathrm{MB}$ onto activated carbons

\begin{tabular}{|c|c|c|c|c|c|c|c|}
\hline \multirow[t]{2}{*}{ Activated Carbon } & \multicolumn{3}{|l|}{ Freundlich model } & \multicolumn{4}{|c|}{ Langmuir model } \\
\hline & $K_{\mathrm{F}} \mathrm{mg} / \mathrm{g}(\mathrm{mg} / \mathrm{L})^{n}$ & $1 / n$ & $\mathrm{R}^{2}$ & $Q_{0}(\mathrm{mg} / \mathrm{g})$ & $K_{\mathrm{L}}(\mathrm{L} / \mathrm{mg})$ & $R_{\mathrm{L}}$ & $R^{2}$ \\
\hline C16 & 21.2 & 0.182 & 0.937 & 62.2 & 0.050 & 0.053 & 0.750 \\
\hline $\mathrm{C} 28$ & 52.0 & 0.182 & 0.973 & 137.3 & 0.176 & 0.016 & 0.840 \\
\hline C37 & 51.6 & 0.224 & 0.964 & 152.9 & 0.608 & 0.006 & 0.987 \\
\hline C64 & 142.6 & 0.199 & 0.971 & 444.0 & 0.900 & 0.004 & 0.941 \\
\hline
\end{tabular}



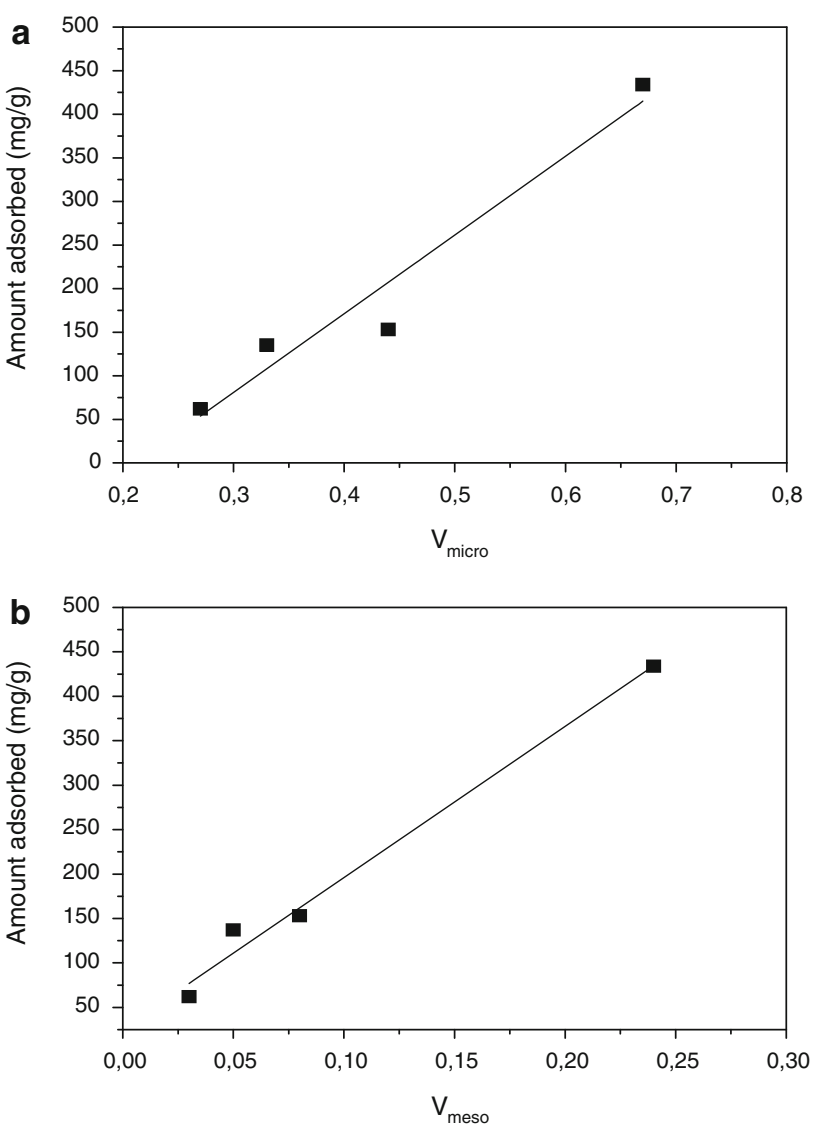

Fig. 4 Amount adsorbed of methylene blue as a function of a micropore volume ( $V \mathrm{o}$, obtained from the $\mathrm{N}_{2}$ adsorption at $77 \mathrm{~K}$ ) and b volume of mesopores $\left(V_{\text {mes }}\right)$

units we have used for $C_{\mathrm{e}}$ ) and the results in Table 3 and Fig. 3 indicate that as predicted there is in fact good agreement between the $K_{\mathrm{F}}$ values and the experimental isotherms. On the other hand, it is noteworthy that each $K_{\mathrm{F}}$ is significantly lower than the corresponding value of $Q_{\mathrm{L}}$. It should therefore be evident that $K_{\mathrm{F}}$ is not a measure of the total adsorption capacity but that it should be considered, a comparative measure of the adsorption under specified conditions.

The results show that the value of $1 / n_{\mathrm{F}}$ is less than unity indicating that the dye is favorably adsorbed by the activated carbons. This is in great agreement with the findings regarding to $R_{\mathrm{L}}$ values (Belala et al. 2011; Dhar Dwivedi et al. 2011).

\section{Redlich-Peterson and Sips equations}

The three-parameter model, R-P and Sips equations have also been applied to evaluate the fit by isotherm for the adsorption of $\mathrm{Mb}$ by Fig. 3a, b. The calculated isotherm parameters and their corresponding coefficient of determination, $R^{2}$, values are shown in Table 4. The higher $R^{2}$ values for the three-parameter isotherms suggest the applicability of these models to represent the equilibrium sorption of MB by activated carbon of date pits. There is good agreement between corresponding values of $Q_{\mathrm{s}}$ and $Q_{\mathrm{L}}$ for $\mathrm{C} 37$ and $\mathrm{C} 64$ samples, while the corresponding values of $Q_{\mathrm{L}}$ for C16 and C28 are lower, probably because these samples do not obey Langmuir isotherm. It is believed that adsorption capacity obtained from the Sips equation could be more realistic than that from the Langmuir equation.

By analogy between Redlich-Peterson and Langmuir equations, we might have expected that the ratio $K_{\mathrm{RP}} / a_{\mathrm{R}}$, would be related to the adsorption monolayer capacity. From Table 4 , the results show that the $K_{\mathrm{RP}} / a_{\mathrm{R}}$ has a similar variation to $Q_{\mathrm{L}}$. Thus, for each parameter, the values show an increase with increasing pore volume and surface area of activated carbons.

It was reported that, $\beta$, is considered a measure of the adsorption affinity (Juang et al. 1996; Haghseresth and $\mathrm{Lu}$ 1998). There is a reasonable agreement between the corresponding values of $\beta$ and $1 / n_{\mathrm{F}}$. It is clear that $\beta$ value approaches unity when the isotherm data best fit Langmuir equation. Thus, Langmuir is a special case of RedlichPeterson when the constant $\beta$ equals unity. However, the parameter $n_{\mathrm{F}}$ appears to be more useful for characterizing the adsorption affinity.

\section{Conclusions}

The isotherm data can well be fitted with four adsorption isotherm models by nonlinear regression. The applicability

Table 4 Redlich-Peterson and Sips isotherms constants for the adsorption of MB onto activated carbons

\begin{tabular}{|c|c|c|c|c|c|c|c|c|}
\hline \multirow[t]{2}{*}{ Activated Carbon } & \multicolumn{4}{|c|}{$\mathrm{R}-\mathrm{P}$ model } & \multicolumn{4}{|c|}{ Sips model } \\
\hline & $K_{R}$ & $a_{\mathrm{R}}$ & $\beta$ & $R^{2}$ & $Q_{S}$ & $K_{\mathrm{S}}$ & $n_{\mathrm{S}}$ & $R^{2}$ \\
\hline $\mathrm{C} 16$ & $8.0 \mathrm{E} 6$ & 3.7E5 & 0.817 & 0.938 & 85.1 & 0.414 & 0.228 & 0.968 \\
\hline $\mathrm{C} 28$ & $1,508.5$ & 27.1 & 0.831 & 0.975 & 147.0 & 0.606 & 0.446 & 0.950 \\
\hline $\mathrm{C} 37$ & $1,28.3$ & 1.1 & 0.927 & 0.991 & 154.9 & 0.592 & 0.892 & 0.987 \\
\hline C64 & $1,912.1$ & 8.0 & 0.891 & 0.981 & 460.2 & 0.935 & 0.550 & 0.967 \\
\hline
\end{tabular}


of Freundlich, Langmuir, Redlich-Peterson and Sips equations can produce consistent results, even though the parameter values are not exactly the same. The threeparameter equations (Redlich-Peterson and Sips) provide better fitting than the two-parameter equations (Freundlich and Langmuir), which is due to the fact that these equations contains three parameters. The adsorption capacity as estimated by the parameters $Q_{\mathrm{s}}, Q_{\mathrm{L}}, K_{\mathrm{RP}} / a_{\mathrm{R}}$ and $K_{\mathrm{R}}$, is strongly influenced by micropore and mesopore volumes of activated carbons. According to the results obtained, activated carbon issued from date stones could be employed as effective adsorbents and could be considered as an alternative to adsorbents for the removal of color.

Open Access This article is distributed under the terms of the Creative Commons Attribution License which permits any use, distribution and reproduction in any medium, provided the original author(s) and source are credited.

\section{References}

Allen SJ, Gan Q, Matthews R, Johnson PA (2003) Comparison of optimised isotherm models for basic dye adsorption by kudzu. Bioresour Technol 88:143-152

Altenor S, Carene B, Emmanuel E, Lambert J, Ehrhardt JJ, Gaspard S (2009) Adsorption studies of methylene blue and phenol onto vetiver roots activated carbon prepared by chemical activation. J Hazard Mater 165:1029-1039

Bansal RC, Goyal M (eds) (2005) Activated Carbon Adsorption, Taylor and Francis Group

Belala Z, Jeguirim M, Belhachemi M, Addoun F, Trouvé G (2011) Biosorption of basic dye from aqueous solutions by Date Stones and Palm-Trees Waste: Kinetic, equilibrium and thermodynamic studies. Desalination 271:80-87

Belhachemi M, Rios RVRA, Addoun F, Silvestre-Albero J, Sepulveda-Escribano A, Rodriguez-Reinoso F (2009) Preparation of activated carbon from date pits: Effect of the activation agent and liquid phase oxidation. J Anal Appl Pyrolysis 86:168-172

Boulinguiez B, Le Cloirec P, Wolbert D (2008) Revisiting the determination of Langmuir parameters application to Tetrahydrothiophene adsorption onto activated carbon. Langmuir 24:6420-6424

Dhar Dwivedi A, Prabha Dubey S, Gopal K, Sillanpää M (2011) Strengthening adsorptive amelioration: Isotherm modeling in liquid phase surface complexation of $\mathrm{Pb}$ (II) and $\mathrm{Cd}$ (II) ions". Desalination 267:25-33

Easton J (1995) Colour in dye house effluent'. Alden Press, Oxford, pp 9-21

Figueiredo JL, Pereira MFR, Freitas MMA, Orfao JJM (1999) Modification of the surface chemistry of activated carbons. Carbon 37:1379-1389

Freundlich HMF (1906) Over the adsorption in solution. Z Phys Chem 57A:385-470

Gaspard S, Altenor S, Dawson EA, Barnes P, Ouensanga A (2007) Activated carbon from vetiver roots: gas and liquid adsorption studies. J Hazard Mater 144:73

Haghseresth F, Lu GQ (1998) Adsorption characteristics of phenolic compounds onto coal-reject-derived adsorbents. Energy Fuels 12:1100-1107

Hall KR, Eagleton LC, Acrivos A, Vermeulen T (1966) Pore-and solid-diffusion kinetics in fixed-bed adsorption under constantpattern conditions. I\&EC Fundam 5:212-223

Ho YS (2004) Selection of Optimum Sorption Isotherm Carbon 42:2115-2116

Juang RS, Wu FC, Tseng RL (1996) Adsorption isotherms of phenolic compounds from aqueous solutions onto activated carbon fibers. J Chem Eng Data 41:487-492

Langmuir I (1916) The constitution and fundamental properties of solids and liquids. J Am Chem Soc 38:2221-2295

Mall ID, Srivastava VC, Agarwal NK (2006) Removal of Orange-G and methyl violet dyes by adsorption onto bagasse fly ashkinetic study and equilibrium isotherm analyses. Dyes and Pigments 69:210-223

Órfão JJM, Silva AIM, Pereira JCV, Barata SA, Fonseca IM, Faria PCC, Pereira MFR (2006) Adsorption of a reactive dye on chemically modified activated carbons-Influence of $\mathrm{pH}$. Colloid and Interf Sc 296:480-489

Redlich O, Peterson DL (1959) A useful adsorption isotherm. J Phys Chem 63:1024

Robinson T, McMullan G, Marchant R, Nigman P (2001) Remediation on dyes in textile effluent: a critical review on current treatment technologies with a proposed alteration. Bioresour Technol 77:247-255

Rodriguez-Reinoso F (1998) The role of carbon materials in heterogeneous catalysis. Carbon 36:159-175

Shafeeyan MS, Ashri Wan Daud WM, Houshmand A, Shamiri A (2010) A review on surface modification of activated carbon for carbon dioxide adsorption. J Anal Appl Pyrolysis 89:143-151

Umpleby RJ, Baxter SC, Chen Y, Shah RN, Shimizu KD (2001) Characterization of molecularly imprinted polymers with the Langmuir-Freundlich isotherm. Anal Chem 212(73):4584 